\title{
Polyethylene Migration from Food Packaging on Cheese Detected by Raman and Infrared (ATR/FT-IR) Spectroscopy
}

\author{
Klytaimnistra Katsara ${ }^{1}$, George Kenanakis ${ }^{2}{ }^{(}$, Zacharias Viskadourakis ${ }^{2}\left(\mathbb{D}\right.$ and Vassilis M. Papadakis ${ }^{1, *(1)}$ \\ 1 Institute of Molecular Biology and Biotechnology, Foundation for Research and Technology-Hellas, \\ N. Plastira 100, GR-70013 Heraklion, Greece; klytaimnistra_katsara@imbb.forth.gr \\ 2 Institute of Electronic Structure and Laser, Foundation for Research and Technology-Hellas, N. Plastira 100, \\ GR-70013 Heraklion, Greece; gkenanak@iesl.forth.gr (G.K.); zach@iesl.forth.gr (Z.V.) \\ * Correspondence: vassilis_papadakis@imbb.forth.gr; Tel.: +30-281-03-912-67
}

Citation: Katsara, K.; Kenanakis, G.; Viskadourakis, Z.; Papadakis, V.M. Polyethylene Migration from Food Packaging on Cheese Detected by Raman and Infrared (ATR/FT-IR) Spectroscopy. Materials 2021, 14, 3872 https://doi.org/10.3390/ma14143872

Academic Editors: Loic Hilliou and Naozumi Teramoto

Received: 10 June 2021

Accepted: 6 July 2021

Published: 12 July 2021

Publisher's Note: MDPI stays neutral with regard to jurisdictional claims in published maps and institutional affiliations.

Copyright: (c) 2021 by the authors. Licensee MDPI, Basel, Switzerland. This article is an open access article distributed under the terms and conditions of the Creative Commons Attribution (CC BY) license (https:/ / creativecommons.org/licenses/by/ $4.0 /)$.

\begin{abstract}
For multiple years, food packaging migration has been a major concern in food and health sciences. Plastics, such as polyethylene, are continuously utilized in food packaging for preservation and easy handling purposes during transportation and storage. In this work, three types of cheese, Edam, Kefalotyri and Parmesan, of different hardness were studied under two complementary vibrational spectroscopy methods, ATR-FTIR and Raman spectroscopy, to determine the migration of low-density polyethylene from plastic packaging to the surface of cheese samples. The experimental duration of this study was set to 28 days due to the degradation time of the selected cheese samples, which is clearly visible after 1 month in refrigerated conditions at $4{ }^{\circ} \mathrm{C}$. Raman and ATR-FTIR measurements were performed at a 4-3-4-3 day pattern to obtain comparative results. Initially, consistency/repeatability measurement tests were performed on Day 0 for each sample of all cheese specimens to understand if there is any overlap between the characteristic Raman and ATR-FTIR peaks of the cheese with the ones from the low-density polyethylene package. We provide evidence that on Day 14 , peaks of low-density polyethylene appeared due to polymeric migration in all three cheese types we tested. In all cheese samples, microbial outgrowth started to develop after Day 21 , as observed visually and under the bright-field microscope, causing peak reverse. Food packaging migration was validated using two different approaches of vibrational spectroscopy (Raman and FTIR), revealing that cheese needs to be consumed within a short time frame in refrigerated conditions at $4{ }^{\circ} \mathrm{C}$.
\end{abstract}

Keywords: food packaging; polyethylene; polymer migration; Raman spectroscopy; FT-IR spectroscopy

\section{Introduction}

Polymeric and plastic packaging has been directly linked to food for decades, as they ensure their delicious, nutritional and aesthetic characteristics while maintaining their nutritional properties for a longer time. A variety of materials have been proposed in the past to preserve and transport food easily, while several research efforts have been focused on innovative technologies and packaging solutions, such as intelligent, recyclable, easy-to-use and antibacterial packing solutions, most of which are polymers, often referred to as plastics [1-3]. There are plenty of plastics, but only some of them are utilized in food packaging; the most common are polyethylene (PE), polyamide (nylon), polyethylene terephthalate (PET), polypropylene (PP), polyvinylidene chloride (PVDC), etc. [1,3]. Among the plastics used in food packaging, mentioned above, PE and especially low-density polyethylene (LDPE) are thinner than some other polymers, while they remain stable up to high temperatures. Due to its toughness and flexibility, LDPE is primarily used in film applications where heat sealing is needed, but it is also used in rigid applications and thus can be used for various types of food packaging, such as beverage, soup wrappers, fruit and vegetable bags used in grocery stores, as well as vacuum packaging of cheese and dairy products [2,4]. However, the nature of the influence of the above plastics on food is 
an open research question, and the suspicion of compound migration remains to be fully addressed. The term "migration" refers to the diffusion of substances from food packaging to the food surface [3,5-12]. In this work, two different vibrational spectroscopic methods (ATR/FT-IR and Raman) were tested to determine the migration of LDPE from plastic packaging to three types of cheese, namely Edam (soft cheese), Kefalotyri (Cretan/Greek semihard cheese) and Parmesan (hard cheese).

We present evidence that that LDPE is indeed migrating from food packaging to all cheese samples, while kept in refrigeration temperatures $\left(\sim 4{ }^{\circ} \mathrm{C}\right)$, and migration is detectable by the spectroscopic techniques from Day 14.

\section{Materials and Methods}

\subsection{Samples and Experiment Preparation}

The experimental design was based on the selected cheese degradation time, which is clearly visible after 1 month in refrigerated conditions at $4{ }^{\circ} \mathrm{C}$. For this reason, the experimental duration was set to 28 days, with consecutive time intervals of 3 and 4 days to allow measurements always within working days. In particular, the measurement days alternated at 4-3-4-3 day pattern (2 measurement days per week, always on Mondays and Thursdays). This approach resulted in 9 time points for every cheese, named Day ${ }_{0}$, Day $_{4}$, Day7, Day11, Day14, Day18, Day21, Day25 and Day28.

Twenty-four resealable air-tight food-grade LDPE pouches, single-layered of $170 \mu \mathrm{m}$ thickness, were bought from a local distributor. They were prepared and premarked with the assigned measurement day and cheese type. Three different kinds of cheese, Edam (soft cheese, fat: $29 \mathrm{~g} / 100 \mathrm{~g}$ ), Kefalotyri (Cretan semihard cheese, fat: $25 \mathrm{~g} / 100 \mathrm{~g}$ ) and Parmesan (hard cheese, fat: $28 \mathrm{~g} / 100 \mathrm{~g}$ ), were prepared for this experiment. Initially, all cheese surfaces touching the packaging were removed. The cleaned cheese was cut into small square pieces and then placed into the premarked LDPE pouches as shown in Figure 1. Air was manually removed (by hand pressure) from the cheese-LDPE interface, ensuring direct contact, and then pouches were well sealed. To avoid any possibility of polymer migration at Day, the first sample from each cheese type was measured right after cutting. For reference purposes, the cheese surface spectral information was acquired on Day $_{0}$, where cheese surface was intact, and in particular without having touched the LDPE pouch. The remaining samples were stored inside a refrigerator at $4{ }^{\circ} \mathrm{C}$ and measured on the corresponding measurement day premarked on the LDPE pouch.
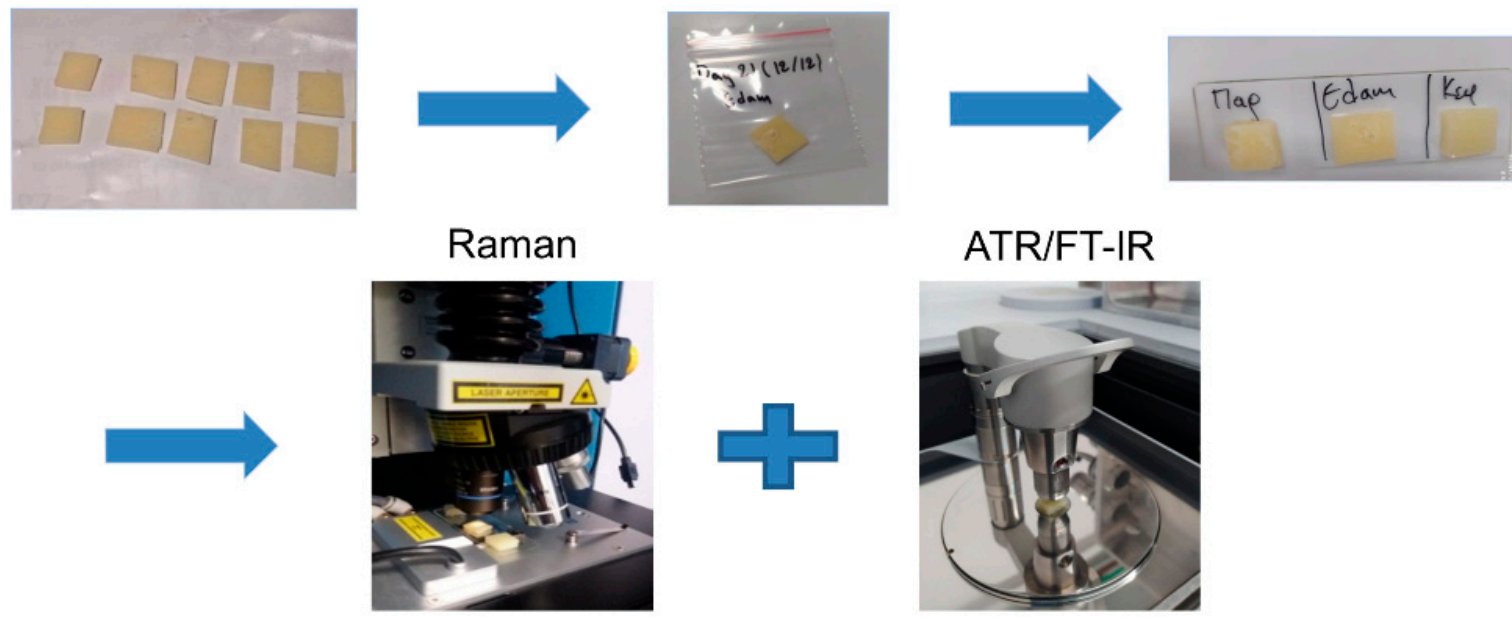

Figure 1. Sample preparation process.

\subsection{Data Acquisition}

Data acquisition was performed with three state-of-the-art instruments located in our premises. In particular, we used a modified Raman microscope (LabRAM HR; HORIBA FRANCE SAS, Longjumeau, France), an ATR/FT-IR spectrometer (Vertex 70v; Bruker 
Optik GmbH, Rosenheim, Germany) coupled with a Bruker A225/Q Platinum ATR unit (Bruker Optik GmbH, Rosenheim, Germany) with single reflection diamond crystal and an X-ray diffractometer (D8 Advance Bruker Optik GmbH, Rosenheim, Germany).

\subsubsection{Instrument Description and Acquisition Settings LabRAM HR Raman Microscope}

A LabRAM HR confocal Raman microscope equipped with an excitation laser line of a central wavelength at $532 \mathrm{~nm}$ and a laser output power of $\sim 100 \mathrm{~mW}$. The objective lens used was an Olympus $50 \times$ lens with a numerical aperture (NA) of 0.5 and a working distance of $10.6 \mathrm{~mm}$ (LMPlanFLN 50X/0.5, Olympus, Tokyo, Japan). The resulting maximum laser power on the sample under the aforementioned setup was measured to be $33 \mathrm{~mW}$ with a laser spot of $\sim 1.3 \mu \mathrm{m}$. A grating of 600 groves was used that resulted in a Raman spectral resolution of around $2 \mathrm{~cm}^{-1}$. The Raman signal detector was a Syncerity CCD Deep Cooled Camera by Horiba, operating at $-50^{\circ} \mathrm{C}$. A temperature-controlled stage (PE120$\mathrm{XY}$, Linkam Scientific Instruments Ltd.; Surrey, UK) coupled with the microscope stage, ensured sample's temperature control and stability. Instrument calibration was performed before each experiment; spectral calibration was performed with a Si reference sample, presenting a single peak at $520.7 \mathrm{~cm}^{-1}$. The microscope was set to acquire Raman spectra from 300 up to $3150 \mathrm{~cm}^{-1}$, while the $532 \mathrm{~nm}$ excitation laser operated at maximum intensity $(100 \%)$ resulting in $33 \mathrm{~mW}$ on the sample. Acquisition time was set to $10 \mathrm{~s}$, and there were 3 spectral accumulations, resulting in a total acquisition time of around $30 \mathrm{~s}$ for every point. All measurements were performed under a constant temperature at $18^{\circ} \mathrm{C}$, using a Linkam PE120 thermoelectrically cooled stage. At the time of measurement, samples were placed onto a glass microscope slide using forceps, maintaining the orientation they had in the LDPE pouches. From each sample, more than 3 measurements at different points were acquired to check for Raman signal consistency. All measurements were acquired around the middle area of the cheese samples.

\section{ATR/FT-IR}

ATR/FT-IR (absorbance) experiments were carried out using a Bruker Vertex 70v FT-IR vacuum spectrometer, equipped with an A225/Q Platinum ATR unit with single reflection diamond crystal which allows the infrared analysis of unevenly shaped solid samples through total reflection measurements, in a spectral range of $7500-350 \mathrm{~cm}^{-1}$. A broadband $\mathrm{KBr}$ beamsplitter (Bruker Optik $\mathrm{GmbH}$, Rosenheim, Germany) and a room temperature broadband triglycine sulfate (DTGS) detector (Bruker Optik GmbH, Rosenheim, Germany) were used, while interferograms were collected at $4 \mathrm{~cm}^{-1}$ resolution (8 scans), apodized with a Blackman-Harris function and Fourier transformed with two levels of zero filling to yield spectra encoded at $2 \mathrm{~cm}^{-1}$ intervals. Before scanning the samples, a background diamond crystal was recorded, and each sample spectrum was obtained by automatic subtraction of it. For each measurement, the samples were carefully placed under the ATR press, maintaining the orientation they had in the pouches, while after every measurement the sample area and the tip of the A225/Q ATR unit were cleaned with pure ethanol (Et-OH; Sigma-Aldrich, Munich, Germany).

XRD

X-ray diffraction (XRD) measurements were performed using a D8 Advance Bruker Optik GmbH (Rosenheim, Germany) diffractometer with Twin-Twin technology, a copper sealed tube $\mathrm{X}$-ray source producing $\mathrm{Cu} \mathrm{k} \alpha$ radiation at a wavelength of $1.5406 \AA$, for 2-theta $=20.00-40.00^{\circ}$ and a speed of $0.01^{\circ} / \mathrm{s}$. 


\subsection{Data Processing and Analysis}

\subsubsection{Spectral References}

Raman Spectral References

The Raman spectrum of LDPE is presented in Figure 2. The major Raman peaks are presented in dashed lines indicating the important Raman peaks on the same graph. The numbering of the Raman peaks is according to ascending wavenumber order.

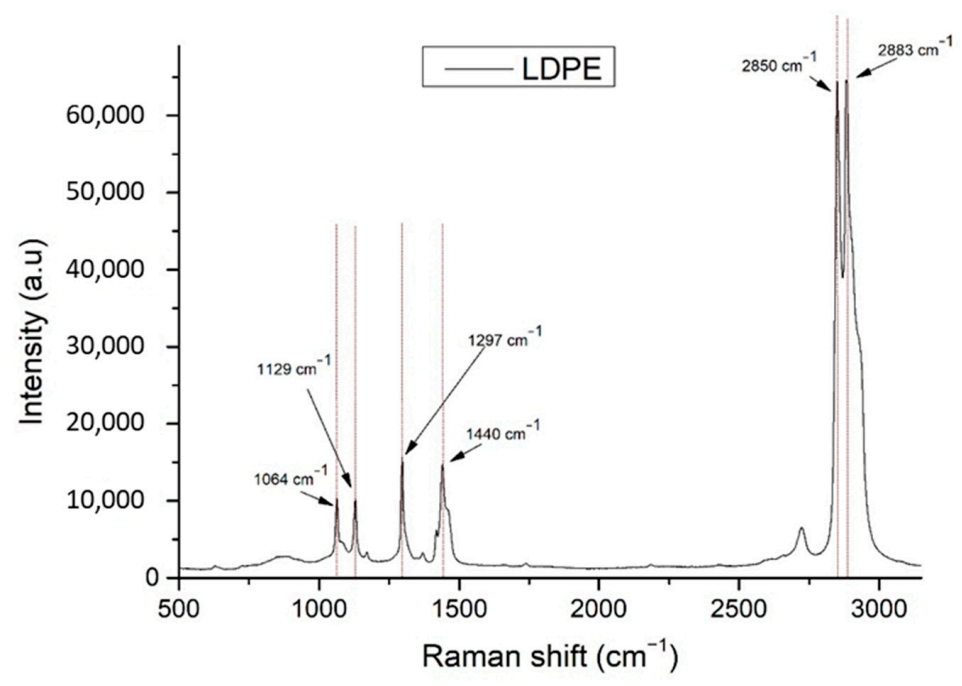

Figure 2. Raman spectrum of LDPE.

In Table 1, the identified Raman peaks of LDPE are presented, according to KnowItAll Informatics System by Bio-Rad Laboratories database. A literature study was performed to identify the related assignments of those LDPE Raman peaks found in existing cheese studies. These assignments are presented in Table 1, together with the associated references.

Table 1. List of the major Raman peak assignments commonly found in cheese and LDPE.

\begin{tabular}{|c|c|c|}
\hline No. & LDPE Major Raman Peaks ( $\left.\mathrm{cm}^{-1}\right)$ & Raman Peak Assignments Found in Cheese Studies $\left(\mathrm{cm}^{-1}\right)$ \\
\hline 1 & 1064 & $\begin{array}{l}1060 \rightarrow \text { C-C skeletal stretching vibration out-of-plane [13] } \\
1065 \rightarrow \mathrm{v}(\mathrm{C}-\mathrm{C}) \text { in fatty acids [14] }\end{array}$ \\
\hline 2 & 1129 & $\begin{array}{l}1125 \rightarrow \mathrm{C}-\mathrm{C} \text { skeletal stretching vibration trans chain conformation in plane [13] } \\
1127 \rightarrow \mathrm{v}(\mathrm{C}-\mathrm{C}) \text { of carotenoids [14] } \\
1132 \rightarrow \text { rocking of } \mathrm{NH}_{3}{ }^{+} \text {in leucine [15] }\end{array}$ \\
\hline 3 & 1297 & $\begin{array}{l}1296 \rightarrow \mathrm{CH}_{2} \text { twist [13] } \\
1301 \rightarrow \mathrm{CH}_{2} \text { twisting mode of phospholipids (phosphatidylcholine, } \\
\text { phosphatidylinositol, phosphatidylserine) [14] } \\
1303 \rightarrow \text { fat band [14], amide III (protein structures) [16] }\end{array}$ \\
\hline 4 & 1440 & $\begin{array}{l}1440 \rightarrow \text { deformation modes of the } \mathrm{CH}_{2} \text { group (in lipids, carbohydrates, amino } \\
\text { acids) [17] } \\
1440,1441 \rightarrow \text { large fat globule, fat band [14] } \\
1442 \rightarrow \mathrm{CH}_{2} \text { scissoring from cholesterol [14] } \\
1444 \rightarrow \text { lipids [16] } \\
1445 \rightarrow \mathrm{CH}_{2} \text { bend scissoring deformation, amide III [13] }\end{array}$ \\
\hline 5 & 2850 & $\begin{array}{l}2850 \rightarrow v_{\mathrm{s}} \mathrm{CH}_{2} \text {, lipids, fatty acids, } \mathrm{CH}_{2} \text { symmetric (especially for biological } \\
\text { tissues) [18] } \\
2852 \rightarrow \text { vibrational modes of lipids [17] }\end{array}$ \\
\hline 6 & 2883 & $\begin{array}{l}2883 \rightarrow \mathrm{CH}_{2} \text { asymmetric stretch of lipids and proteins (especially for biological } \\
\text { tissues) [18] } \\
2880 \rightarrow \text { vibrational modes of lipids [17] }\end{array}$ \\
\hline
\end{tabular}




\section{ATR/FT-IR Spectral References}

The ATR/FT-IR spectrum of LDPE is presented in Figure 3. The major ATR/FTIR peaks are presented in dashed lines indicating the important ATR/FT-IR peaks on the same graph. The numbering of the ATR/FT-IR peaks is according to ascending wavenumber order.

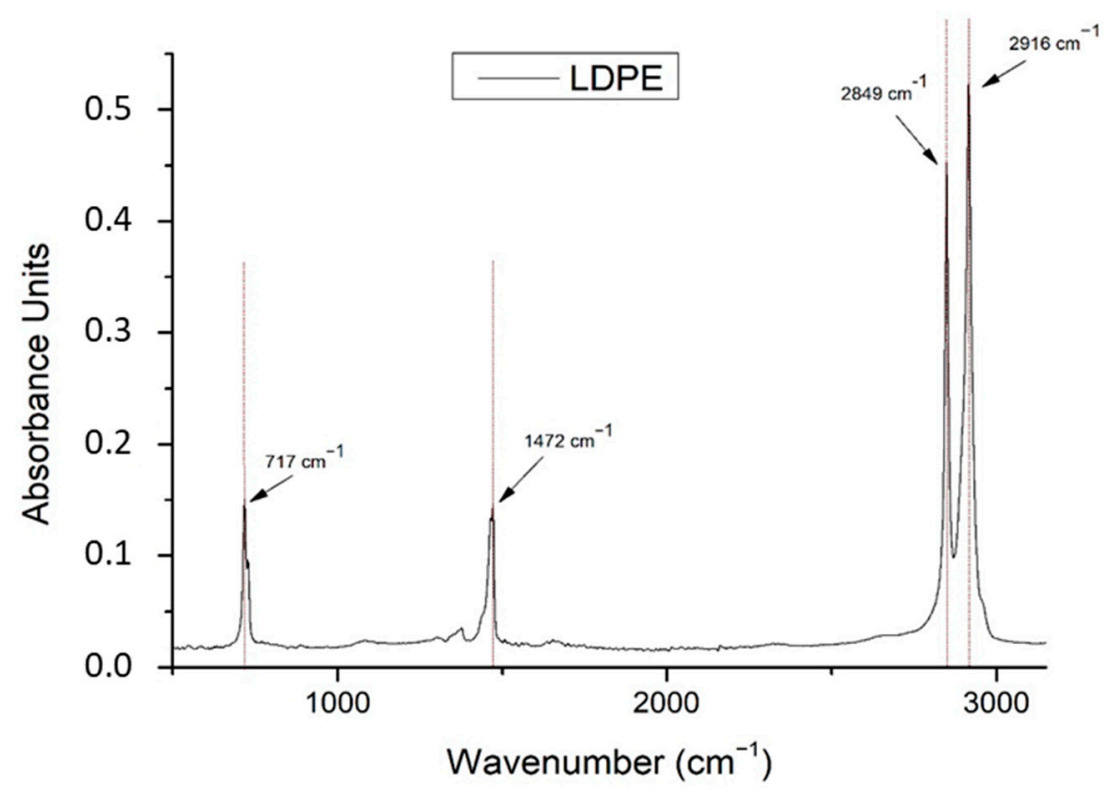

Figure 3. The ATR/FT-IR spectrum of LDPE.

In Table 2, the identified ATR/FT-IR peaks of LDPE are presented, as described in the S.T. Japan Europe GmbH FT-IR database. A literature study was performed to identify the related assignments of those ATR/FT-IR peaks found in existing cheese studies; they are also presented together with the associated references.

Table 2. List of the major ATR/FT-IR LDPE peaks and their assignments.

\begin{tabular}{cll}
\hline No. & LDPE Major ATR/FT-IR Peaks $\left(\mathbf{c m}^{-\mathbf{1}}\right)[19,20]$ & \multicolumn{1}{c}{ ATR/FT-IR Peak Assignments in Cheese Bonds $\left(\mathbf{c m}^{-1}\right)$} \\
\hline 1 & $717 \rightarrow$ rocking vibration of $-\mathrm{CH}_{2}$ in LDPE & \multicolumn{1}{c}{ Does not exist in cheese samples } \\
\hline 2 & $\begin{array}{l}1472 \rightarrow \text { bending vibrations of }-\mathrm{CH}_{2} \text { and }-\mathrm{CH}_{3} \\
\text { in LDPE }\end{array}$ & $\begin{array}{l}950-1490 \rightarrow \text { carbohydrates (lactose and monosaccharides) [21] } \\
1199-1474 \rightarrow \text { O-C-H, C-C-H, C-OH vibrational modes from sugars } \\
\text { and organic acids [22] }\end{array}$ \\
\hline 3 & $2849 \rightarrow$ stretching vibration of $-\mathrm{CH}$ in LDPE & $\begin{array}{l}2850 \rightarrow \mathrm{C}-\mathrm{H} \text { stretching of methylene groups [22] } \\
2851 \rightarrow \text { methylene band ( } \mathrm{CH}_{2} \text { in fat) [21] }\end{array}$ \\
\hline \multirow{2}{*}{$2916 \rightarrow$ stretching vibration of $-\mathrm{CH}_{2}$ in LDPE } & $\begin{array}{l}2920 \rightarrow \mathrm{C}-\mathrm{H} \text { stretching of methylene groups [22] } \\
2920 \rightarrow \text { methylene band ( } \mathrm{CH}_{2} \text { in fat) [21] }\end{array}$ \\
\hline
\end{tabular}

\section{XRD Spectral References}

The XRD pattern of LDPE is presented in Figure 4. The major XRD peaks are presented with arrows indicating the related diffraction angles. 


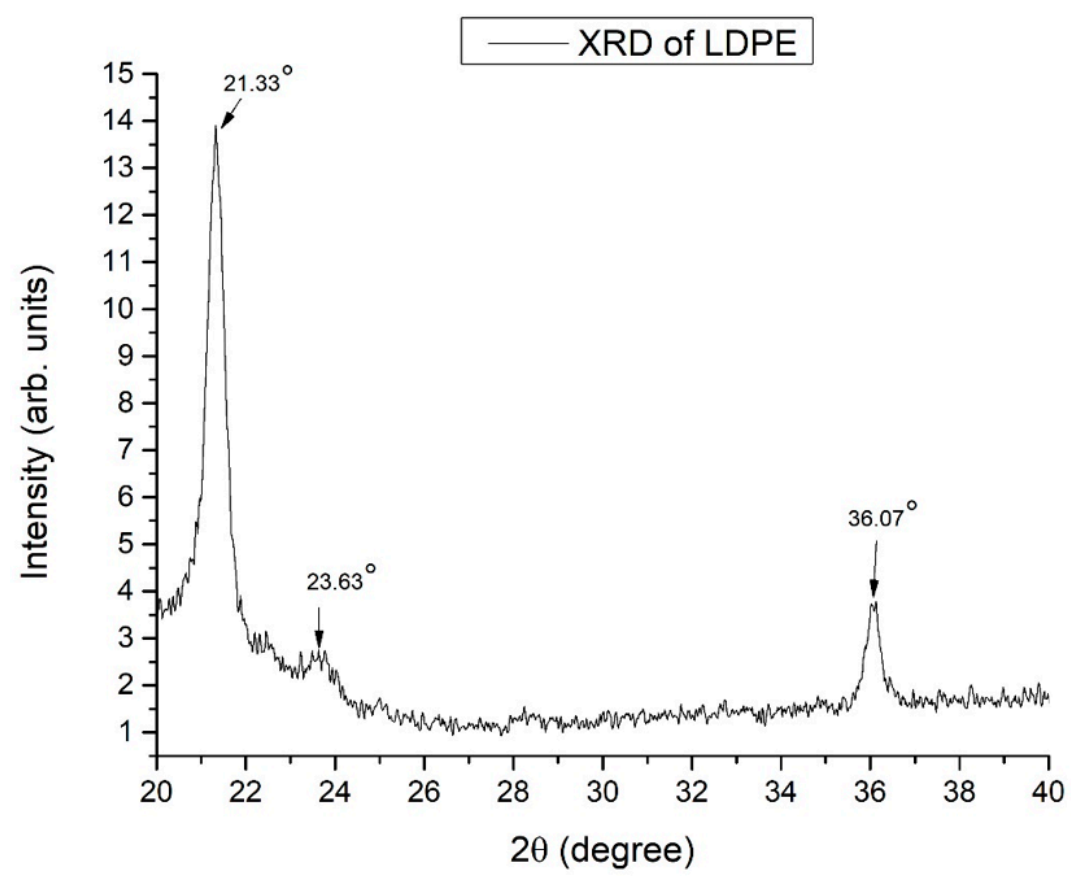

Figure 4. The XRD pattern of LDPE.

Figure 4 shows that the XRD peaks are in accordance with the literature [23-26] and JSPDS card 11-0834, verifying that the packaging material used is indeed LDPE.

In Table 3, the identified XRD peaks of LDPE are presented, as described in [23-26].

Table 3. List of the major XRD LDPE peaks and their assignments [23-26].

\begin{tabular}{ccc}
\hline No. & $\begin{array}{c}\text { LDPE Major Diffraction } \\
\text { Angles }\left({ }^{\circ}\right)\end{array}$ & $\begin{array}{c}\text { LDPE XRD Diffraction } \\
\text { Planes (Miller Indices) }\end{array}$ \\
\hline 1 & 21.33 & $(110)$ \\
\hline 2 & 23.63 & $(200)$ \\
\hline 3 & 36.07 & $(020)$ \\
\hline
\end{tabular}

\subsubsection{Spectra Processing and Analysis}

Raman spectra were acquired, processed, analyzed and visualized by LabSpec 6 Raman software, made by Horiba (HORIBA FRANCE SAS, Longjumeau, France). Additionally, ATR/FT-IR spectra were acquired, processed, analyzed and visualized by Opus 7.2 software, made by Bruker (Bruker Optik GmbH, Rosenheim, Germany). Afterward, all manuscript figures were created with MS Excel (Microsoft Corporation, Washington, DC, USA).

\section{Raman Spectra Processing and Analysis}

For each Raman spectrum, the following processing methodology was used: (a) cosmic rays were removed, (b) background was removed using a 5th-order polynomial function and (c) final spectrum was smoothed under a Gaussian filter with a kernel of 5 points. Afterward, for each cheese measurement, all Day ${ }_{x}$ Raman spectra were then normalized by the first Dayo reference spectrum to observe only the Raman spectral changes throughout the experiment.

\section{ATR/FT-IR Spectra Processing and Analysis}

For each ATR/FT-IR spectrum, the following processing methodology was used: after performing each cheese measurement, as described in Section 2.3.2, all day (Dayx) 
ATR/FT-IR spectra were normalized by the first (Dayo) reference spectrum to observe only the ATR/FT-IR spectral changes throughout the experiment.

\section{Results and Discussion}

\subsection{Spectroscopic Analysis (Raman and ATR/FT-IR Spectroscopy)}

\subsubsection{Consistency/Repeatability Tests}

Initially, we performed a consistency/repeatability test of the measurements on the same sample. For this reason, three measurements at different locations were acquired from each cheese sample. These measurements are presented in Figure 5, with an offset between them to show the actual similarities. As it is shown, measurements were very consistent, presenting high repeatability. We followed this test across all the measurements, always acquiring a minimum of three measurements from each sample. In Figure 5, we also present the consistency/repeatability measurements from our three different cheese samples and on three different days (Day, Day $_{4}$ and Day ${ }_{14}$ ). The standard deviation (SD) of the average at the highest signal peak for each cheese type was at $2889 \mathrm{~cm}^{-1}$ for Raman (Kefalotyri 0.44\%, Edam 11.58\%, Parmesan 7.02\%) and at $2921 \mathrm{~cm}^{-1}$ for ATR/FT-IR (Kefalotyri 16.7\%, Edam 28.15\%, Parmesan 50.9).
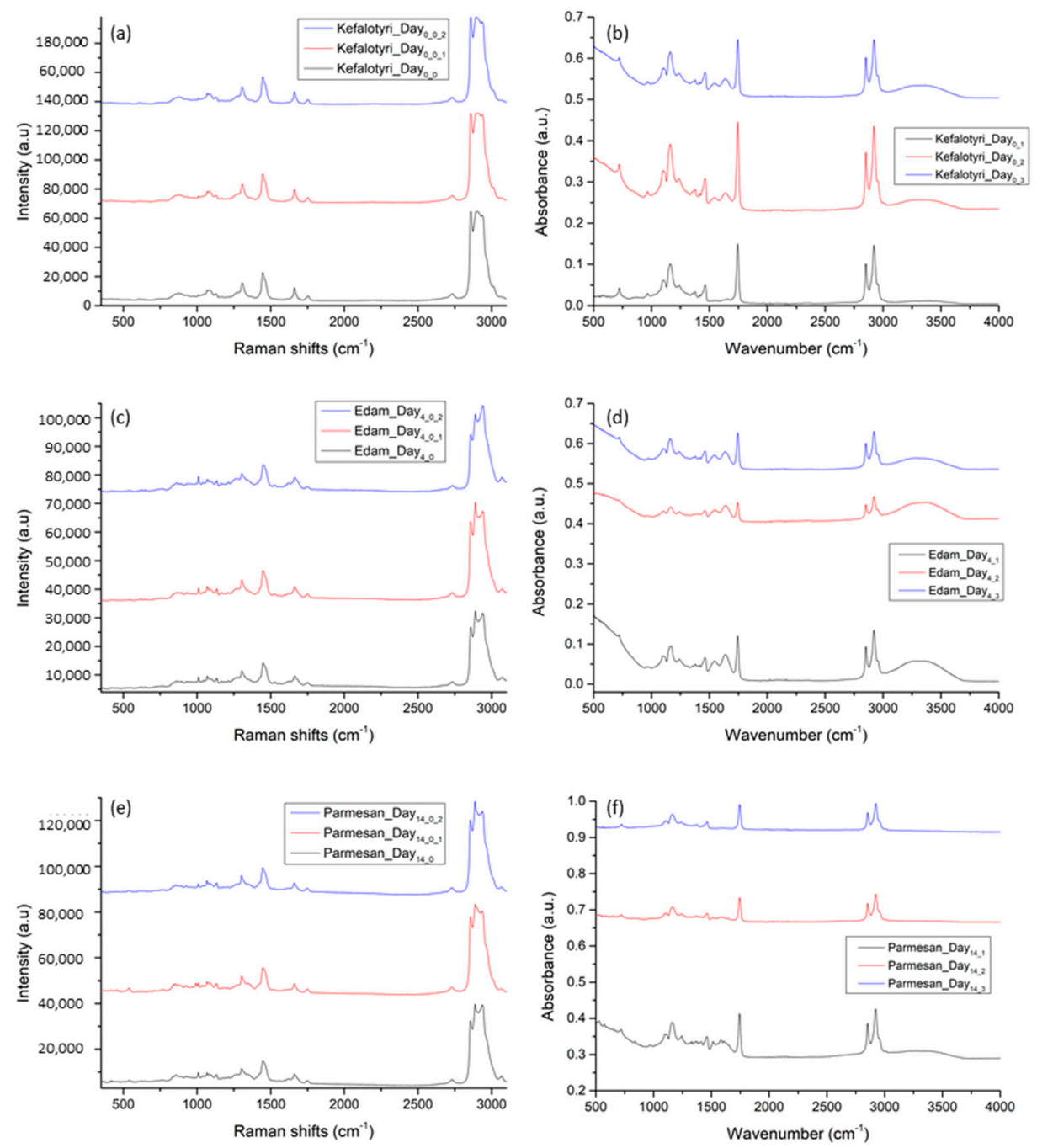

Figure 5. Raman and ATR/FT-IR consistency/repeatability measurements from the 3 different cheese samples: $(\mathbf{a}, \mathbf{b})$ show the Kefalotyri at Day $0,(\mathbf{c}, \mathbf{d})$ Edam at Day ${ }_{4}$, and $(\mathbf{e}, \mathbf{f})$ Parmesan at Day 14 . Spectra are presented in stack-line format, with an offset between them, in order to present the full spectral details in each sample. For this reason, the intensity axis is in arbitrary units. 
At this point, we should comment that, some inconsistencies are present in the measurements after Day 21 that are attributed to the microbial outgrowth (biofilm) that is developed after Day18, or cheese surface oxidation. One example of this degradation is presented in Figure 6, which contains a microscopic picture from Parmesan cheese on Day25.

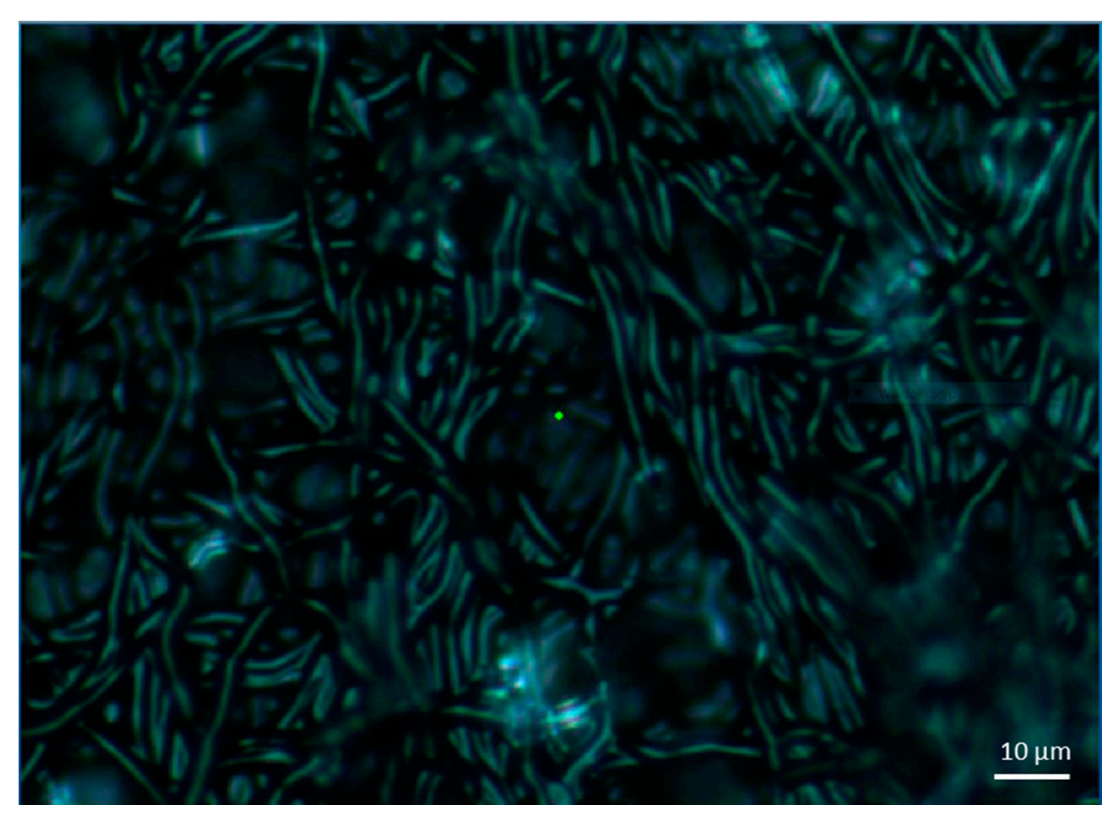

Figure 6. Bright-field picture of the Parmesan cheese sample from Raman microscope on Day25.

\subsubsection{LDPE Detection}

Initially, we measured all cheese samples on Day 0 to understand if there is any overlap between the characteristic Raman and ATR/FT-IR peaks of the cheese samples with the ones from the LDPE package. Raman and ATR/FT-IR measurements are presented in Figure 7. As can be seen, the Raman peaks of LDPE are not present in the cheese spectrum, except only one, at $1129 \mathrm{~cm}^{-1}$; in Kefalotyri cheese, this peak is present at $1131 \mathrm{~cm}^{-1}$, and in Parmesan cheese, it is at $1134 \mathrm{~cm}^{-1}$. Although these Raman peaks from the different cheese samples are not presented exactly at the same LDPE peak of $1129 \mathrm{~cm}^{-1}$, they are very close to this peak and are considered the same. On the contrary, the ATR/FT-IR peaks of LDPE exist in all cheese samples, so the detection of the LDPE migration was focused on the intensity changes.

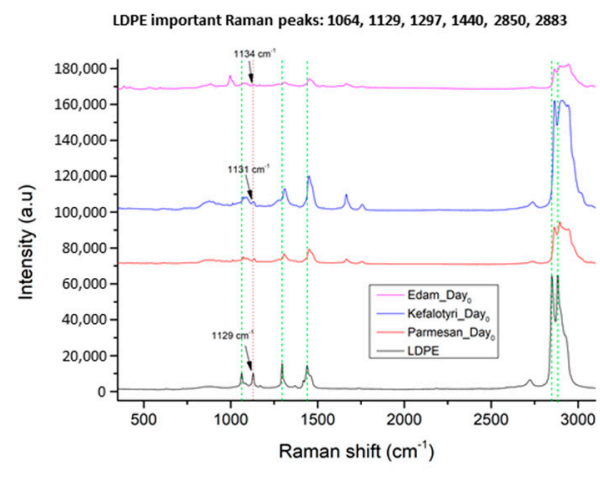

(a)

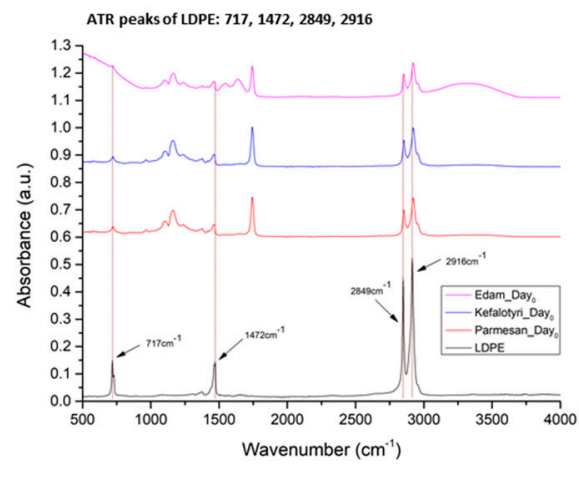

(b)

Figure 7. Reference spectra for (a) Raman and (b) ATR/FT-IR from cheese samples on Day 0 and LDPE. Spectra are presented in stack-line format, with an offset between them, in order to present the full spectral details in each sample. For this reason, the intensity axis is in arbitrary units. 
In each of the following figures, we present the LDPE spectrum, in black color, together with the Day 0 Raman and ATR/FT-IR spectra from each cheese type (Edam, Kefalotyri and Parmesan), in red color, as references. Together with the reference spectra, we show the evolution of the Raman and ATR/FT-IR spectral differences from Day, across selected days. In Figure 8, Raman and ATR/FT-IR spectral differences of Day 14 are presented in blue, those of Day 18 are presented in purple and those of Day 25 are presented in green.

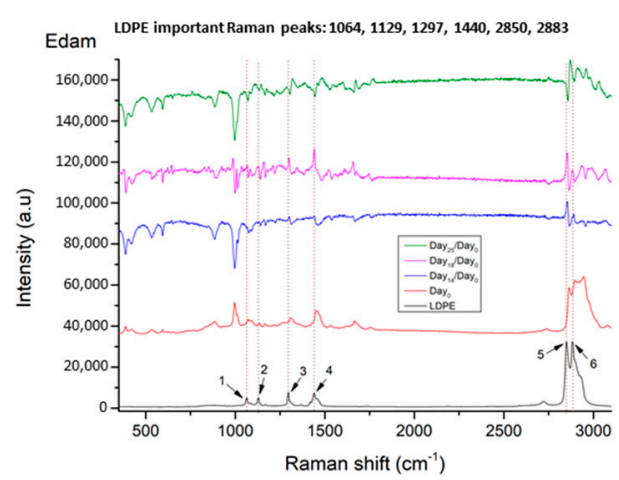

(a)

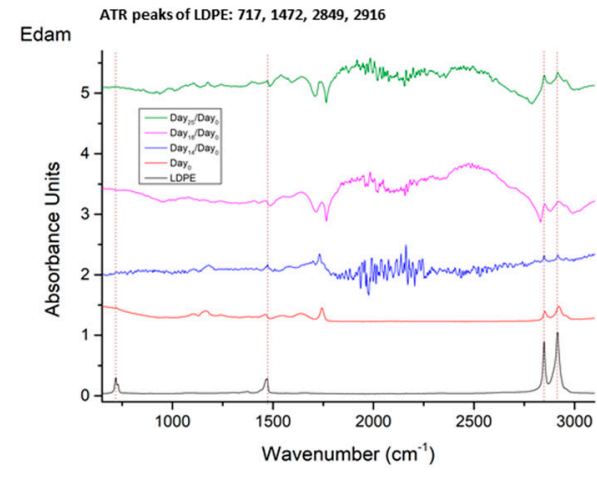

(b)

Figure 8. (a) Raman spectra and (b) ATR/FT-IR spectra, of Edam cheese on different days, in comparison with the LDPE spectrum. Spectra are presented in stack-line format, with an offset between them, in order to present the full spectral details in each sample. For this reason, the intensity axis is in arbitrary units.

As can be seen in the Raman and the ATR/FT-IR spectral differences in Figure 8, from Day $_{14}$, all LDPE peaks start to appear in Edam cheese, and on Day ${ }_{18}$, these peaks become more distinct. The fact that we observe no differences in the first day that LDPE peaks appear in our study restricts us from comparing the differences in fat content between the cheese types as described in related studies $[7,27]$. On Day ${ }_{25}$, these peaks are reversed, probably due to surface oxidation or the presence of biofilm developing. This is also observed in the cheese visually and under the bright-field microscope, starting from Day 21 .

A similar behavior is found in Kefalotyri cheese. As we observe in Figure 9, on Day 14 and Day 18 for Raman and ATR/FT-IR spectra, respectively, LDPE peaks appear with a gradual increase across the days. Again, on $\mathrm{Day}_{25}$ these peaks are reversed, probably due to oxidation or the presence of the biofilm developing in the cheese surface. This was verified visually and under the bright-field microscope, clearly obvious on Day 25 .

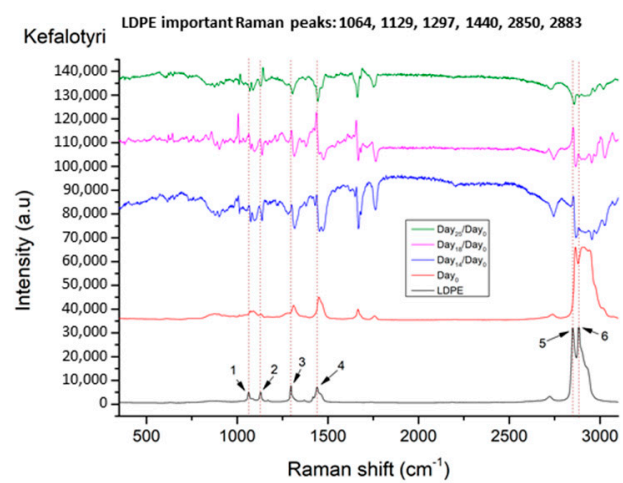

(a)

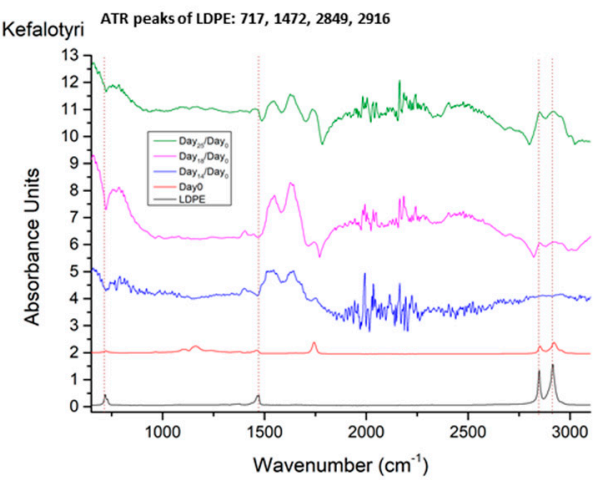

(b)

Figure 9. (a) Raman and (b) ATR/FT-IR spectra, of Kefalotyri cheese on different days, in comparison with the LDPE spectrum. Spectra are presented in stack-line format, with an offset between them, in order to present the full spectral details in each sample. For this reason, the intensity axis is in arbitrary units. 
Parmesan cheese was the most stable one, concerning the oxidation of the cheese surface and the development of the biofilm. As we observe from Figure 10, on Day ${ }_{14}, \mathrm{LDPE}$ peaks start to appear in both techniques. On Day18, these peaks for Raman increase and become more distinct, while no significant changes were observed for the sample used in ATR/FT-IR, probably due to a sample error. On Day25, similarly to the other cheese samples, these peaks have been reversed for Raman, although no visible degradation was found visually or under the bright-field microscope. For ATR/FT-IR, we observed an increase in the LDPE peaks. Following the spectral differences from Day, we can be sure that there is no interplay between the LDPE characteristic peaks and the cheese Raman signal behavior throughout the days. Furthermore, the spectral features from both Raman and ATR/FT-IR present in the later experimental days, where oxidation and/or biofilm starts to develop, showing that there is no direct correlation with the LDPE spectral features measured. Taking this into account, together with the fact that all LDPE peaks are present from Day 14 , proves that the Raman and ATR/FT-IR spectra identified are most probably from the polymer itself, with the further understanding that our instruments' sensitivity managed to detect those peaks only after Day 14 . We make this statement to clarify that LDPE migration might have already been initiated in earlier days, but the concentration of the polymeric migration is not sufficient to be detected with our instrumentation.

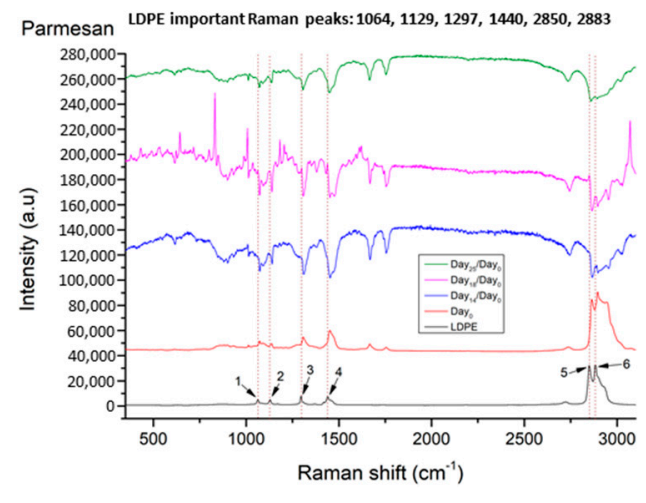

(a)

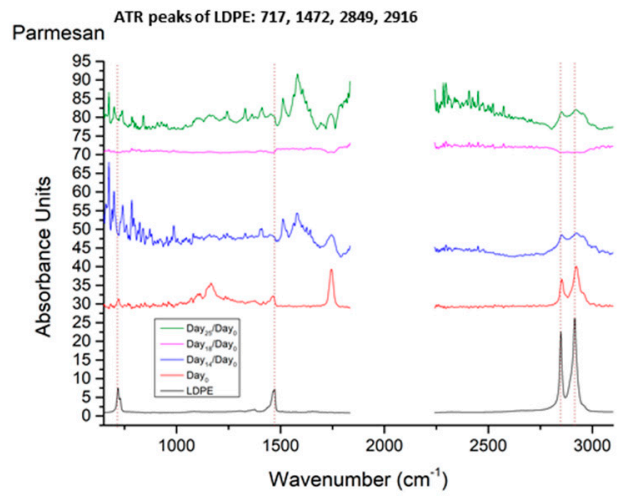

(b)

Figure 10. (a) Raman and (b) ATR/FT-IR spectra, of Parmesan cheese on different days, in comparison with the LDPE spectrum. Spectra are presented in stack-line format, with an offset between them, in order to present the full spectral details in each sample. For this reason, the intensity axis is in arbitrary units.

\section{Conclusions}

In this work, we show that LDPE migration from food packaging is indeed occurring in three different cheese samples in refrigeration temperatures $\left(4^{\circ} \mathrm{C}\right)$. Based on our experimental setup, we managed to observe this polymeric migration through time, firstly identifying it on Day 14 , in all three cheese types we tested. The LDPE migration was validated with two independent techniques, Raman and ATR/FT-IR spectroscopy. An efficient and simple vibrational spectral measurement methodology is presented that enabled us to achieve fast and robust measurements for LDPE migration detection.

Author Contributions: Conceptualization and methodology, G.K. and V.M.P.; bibliographic investigation, K.K., G.K. and V.M.P.; experimental characterization and analysis, K.K., G.K., Z.V. and V.M.P.; funding acquisition G.K. and V.M.P. All authors have read and agreed to the published version of the manuscript.

Funding: This work was financially supported by the project "Advanced Research Activities in Biomedical and Agro alimentary Technologies" (MIS 5002469) which is implemented under the "Action for the Strategic Development on the Research and Technological Sector", funded by the Operational Programme "Competitiveness, Entrepreneurship and Innovation" (NSRF 2014-2020) 
and co-financed by Greece and the European Union (European Regional Development Fund); the BIOIMAGING-GR (MIS 5002755) implemented under "Action for Strengthening Research and Innovation Infrastructures," funded by the Operational Programme "Competitiveness, Entrepreneurship and Innovation" (NSRF 2014-2020) and co-financed by Greece and the European Union (European Regional Development Fund); and the Stavros Niarchos Foundation within the framework of the project ARCHERS ("Advancing Young Researchers' Human Capital in Cutting Edge Technologies in the field of Systems Biology Approaches and Personal Genomics for Health and Disease Treatment"). Finally, author G.K. acknowledges project "NanoBioPack" (MIS 5056214), funded by GSRT special actions: Aquaculture-Industrial materials-Open innovation culture, Greek General Secretariat for Research and Technology (GSRT), Greece.

Institutional Review Board Statement: Not applicable.

Informed Consent Statement: Not applicable.

Data Availability Statement: All data reported here can be made available upon request.

Conflicts of Interest: The authors declare no conflict of interest.

\section{References}

1. Arvanitoyannis, I.S.; Bosnea, L. Migration of Substances from Food Packaging Materials to Foods. Crit. Rev. Food Sci. Nutr. 2004, 44, 63-76. [CrossRef]

2. Robertson, G.L. Food Packaging Principles and Practice, 2nd ed.; CRC Press: Raton, FL, USA; Taylor and Francis Group: Raton, FL, USA, 2006.

3. Bhunia, K.; Sablani, S.S.; Tang, J.; A Rasco, B. Migration of Chemical Compounds from Packaging Polymers during Microwave, Conventional Heat Treatment, and Storage. Compr. Rev. Food Sci. Food Saf. 2013, 12, 523-545. [CrossRef] [PubMed]

4. Crompton, T. Additive Migration from Plastics into Food, 1st ed.; Elsevier: Oxford, UK, 2007.

5. Mauricio-Iglesias, M.; Guillard, V.; Gontard, N.; Peyron, S. Application of FTIR and Raman microspectroscopy to the study of food/packaging interactions. Food Addit. Contam. Part A 2009, 26, 1515-1523. [CrossRef]

6. Begley T, C.L.; Feigenbaum, A.; Franz, R.; Hinrichs, K.; Lickly, T.; Mercea, P.; Milana, M.; O’Brien, A.; Rebre, S.; Rijk, R.; et al. Evaluation of migration models that might be used in support of regulations for food contact plastics. Food Addit. Contam. 2005, 22, 73-90. [CrossRef]

7. John, N.; Hahladakisa, C.A.; Velis, A.; Roland, W.; Eleni, I.; Phil, P. An overview of chemical additives present in plastics: Migration, release, fate and environmental impact during their use, disposal and recycling. J. Mater. 2018, 344, 179-199.

8. Fasihnia, S.H.; Peighambardoust, S.H.; Peighambardoust, S.J.; Oromiehie, A.; Soltanzadeh, M.; Peressini, D. Migration analysis, antioxidant, and mechanical characterization of polypropylene-based active food packaging films loaded with BHA, BHT, and TBHQ. J. Food Sci. 2020, 85, 2317-2328. [CrossRef] [PubMed]

9. Pax, A.; Ong, L.; Vongsvivut, J.; Tobin, M.J.; Kentish, S.E.; Gras, S.L. The characterisation of Mozzarella cheese microstructure using high resolution synchrotron transmission and ATR-FTIR microspectroscopy. Food Chem. 2019, 291, 214-222. [CrossRef] [PubMed]

10. Ibarra, V.A.G.; De Quirós, A.R.B.; Losada, P.P.; Sendón, R. Identification of intentionally and non-intentionally added substances in plastic packaging materials and their migration into food products. Anal. Bioanal. Chem. 2018, 410, 3789-3803. [CrossRef] [PubMed]

11. El-Ziney, M.G. Migration Levels of Monostyrene from Polystyrene Containers to Dairy Products. MOJ Food Process. Technol. 2016, 3. [CrossRef]

12. Maia, J.; De Quirós, A.R.-B.; Sendón, R.; Cruz, J.M.; Seiler, A.; Franz, R.; Simoneau, C.; Castle, L.; Driffield, M.; Mercea, P.; et al. The Determination of Key Diffusion and Partition Parameters and Their Use in Migration Modelling of Benzophenone from Low Density Polyethylene (LDPE) into different Foodstuffs. Food Addit. Contam. Part A 2016, 33, 715-724. [CrossRef] [PubMed]

13. Burdikova, Z.; Svindrych, Z.; Hickey, C.; Wilkinson, M.G.; Auty, M.A.; Samek, O.; Bernatova, S.; Krzyzanek, V.; Periasamy, A.; Sheehan, J.J. Application of advanced light microscopic techniques to gain deeper insights into cheese matrix physico-chemistry. Dairy Sci. Technol. 2015, 95, 687-700. [CrossRef]

14. Smith, G.P.; Holroyd, S.E.; Reid, D.C.; Gordon, K.C.; Geoffrey, P.S.; Smith, S.E.H.; David, C.W.R.; Gordona, K.C. Raman imaging processed cheese and its components. J. Raman Spectrosc. 2016, 48, 374-383. [CrossRef]

15. D'Incecco, P.; Limbo, S.; Faoro, F.; Hogenboom, J.; Rosi, V.; Morandi, S.; Pellegrino, L.M. New insight on crystal and spot development in hard and extra-hard cheeses: Association of spots with incomplete aggregation of curd granules. J. Dairy Sci. 2016, 99, 6144-6156. [CrossRef]

16. AMECA. Chapter 10 Identifying Sensory Attributes for A Functional "Ideal Beverage" for Cirrhotic Patients. In Book of Proceedings Latin Food 2018; 8th Food Science, Biotechnology \& Safety Congress: Puerto Vallarta, Jalisco, Mexico, 2018.

17. de Sá Oliveira, K.; de Souza Callegaro, L.; Stephani, R.; Almeida, M.R.; de Oliveira, L.F.C. Analysis of spreadable cheese by Raman spectroscopy and chemometric tools. Food Chem. 2016, 194, 441-446. [CrossRef] 
18. Talari, A.C.S.; Movasaghi, Z.; Rehman, S.; Rehman, I.U. Raman Spectroscopy of Biological Tissues. Appl. Spectrosc. Rev. 2015, 50, 46-111. [CrossRef]

19. Lin, J.-H.; Pan, Y.-J.; Liu, C.-F.; Huang, C.-L.; Hsieh, C.-T.; Chen, C.-K.; Lin, Z.-I.; Lou, C.-W. Preparation and Compatibility Evaluation of Polypropylene/High Density Polyethylene Polyblends. Materials 2015, 8, 8850-8859. [CrossRef]

20. Karlsson, W.C.a.S. NIR, DSC, and FTIR as Quantitative Methods for Compositional Analysis of Blends of Polymers Obtained from Recycled Mixed Plastic Waste. Polym. Eng. Sci. 2001, 41, 1626-1635.

21. Martin-del-Campoa, S.T.; Cosio-Ramirezb, D.P.R.; Corrieua, G. Middle infrared spectroscopy characterization of ripening stages of Camembert-type cheeses. Int. Dairy J. 2007, 17, 835-845. [CrossRef]

22. Koca, N.; Rodriguez-Saona, L.; Harper, W.; Alvarez, V. Application of Fourier Transform Infrared Spectroscopy for Monitoring Short-Chain Free Fatty Acids in Swiss Cheese. J. Dairy Sci. 2007, 90, 3596-3603. [CrossRef]

23. Nguyen, V.G.; Thai, H.; Mai, D.H.; Tran, H.T.; Tran, D.L.; Vu, M.T. Effect of titanium dioxide on the properties of polyethylene/TiO 2 nanocomposites. Compos. Part B Eng. 2013, 45, 1192-1198. [CrossRef]

24. Madani, M. Structure, optical and thermal decomposition characters of LDPE graft copolymers synthesized by gamma irradiation. Curr. Appl. Phys. 2011, 11, 70-76. [CrossRef]

25. Marinkovic, F.S.; Popovic, D.M.; Jovanovic, J.D.; Stankovic, B.S.; Adnadjevic, B.K. Methods for quantitative determination of filler weight fraction and filler dispersion degree in polymer composites: Example of low-density polyethylene and NaA zeolite composite. Appl. Phys. A 2019, 125, 611. [CrossRef]

26. Alsaygh, A.A.; Al-Hamidi, J.; Alsewailem, F.D.; Al-Najjar, I.M.; Kuznetsov, V.L. Characterization of polyethylene synthesized by zirconium single site catalysts. Appl. Petrochem. Res. 2014, 4, 79-84. [CrossRef]

27. Cooper, I.; Tice, P.A. Migration studies on fatty acid amide slip additives from plastics into food simulants. Food Addit. Contam. 1995, 12, 235-244. [CrossRef] 